\title{
Modelos de predicción de propagación para señales de televisión en la banda UHF
}

\author{
Elvis E. Gaona*, Edgar A. López y Juan C. Gómez \\ Universidad Distrital Francisco José de Caldas, Facultad Ingeniería, Bogotá D.C- Colombia. \\ (correo-e: egaona@udistrital.edu.co,ealopezs@correo.udistrital.ed.co,jgomez@udistrital.edu.co). \\ ${ }^{*}$ Autor a quien debe ser dirigida la correspondencia
}

Recibido Oct. 1, 2019; Aceptado Dic. 3, 2019; Versión final Mar. 12, 2020, Publicado Ago. 2020

\begin{abstract}
Resumen
En esta investigación se comparan simulaciones obtenidas utilizando modelos de propagación determinísticos, estadísticos y semi-determinísticos y las mediciones realizadas de cobertura de la señal de televisión digital terrestre para entornos urbanos y rurales en Colombia. Se selecciona un modelo de propagación que más se aproxime a las condiciones del territorio rural colombiano para usarse en la planificación de redes de televisión digital terrestre en la banda UHF, cuyo coeficiente de error puede compensarse con la aplicación de factores de corrección. Los análisis muestran que el modelo de propagación que más se aproxima al escenario real de radiodifusión de señales de televisión para Colombia corresponde a una combinación de los modelos determinísticos ITU-R 525 para entornos con línea de vista despejada. Para entornos con obstrucciones en la línea de vista, se concluye que el modelo de propagación Deygout 94 ofrece mejores resultados.
\end{abstract}

Palabras clave: difracción; intensidad de campo; mediciones en campo; propagación; zona de Fresnel

\section{Prediction models for the propagation for television signals in the UHF band}

\begin{abstract}
This research study compares simulations obtained using deterministic, statistical, and semi-deterministic propagation models to measurements obtained of digital terrestrial television signal coverage for urban and rural environments in Colombia. A propagation model is selected that is most similar to the conditions found in the Colombian rural territory. This is to be used in the planning of digital terrestrial television networks in the UHF band having an error coefficient that can be compensated by applying correction factors. Simulation analyses show that the propagation model that is best suited to the real television broadcasting scenario for Colombia corresponds to a combination of the ITU-R 525 deterministic models for clear line-of-sight environments. For obstructed line-of-sight environments, it is concluded that the Deygout 94 propagation model offers the best results.
\end{abstract}




\section{INTRODUCCIÓN}

En Colombia en el año 2011 se adoptó el estándar de radiodifusión DVB-T2 (Digital Video Broadcasting Second Generation Terrestrial) y se le atribuyó el rango de frecuencia de 470 a $698 \mathrm{MHz}$ en la banda UHF, (ANE, 2012). Éste estándar se desarrolló sobre la base de la importancia del sistema de transmisión abierto, que se apoya en la interoperabilidad y la flexibilidad, tiene ventajas en la confiabilidad con capacidad para enviar grandes cantidades de datos de alta velocidad (Eizmendi et al., 2014), punto a multipunto, utilizando las últimas técnicas de modulación y codificación (Vargas-Arcila et al., 2015) permitiendo el uso eficiente del espectro terrestre para la entrega de servicios de audio, video y datos a dispositivos fijos, portátiles y móviles (Astawa y Santoso, 2016), con una mejor calidad comparado con servicios IPTV (Cuéllar et al., 2014) e IPTVIMS (Avellaneda, et al., 2014).

La planificación de la cobertura de las redes de televisión digital terrestre se limita a una región específica del espectro radioeléctrico, permitiendo identificar aquellos modelos de propagación que se ajusten a las condiciones geográficas del país (Peña, 2017). En ese sentido, los modelos predictivos de propagación se dividen en tres categorías: los modelos determinísticos, que se basan en expresiones matemáticas y que producen el mismo resultado en condiciones similares (ITU-R P.526-13, 2013); los modelos estadísticos se sustentan en resultados experimentales y mediciones realizadas en campo bajo condiciones disimiles de recepción (ITU-R P.1546-5, 2013); y los modelos semi-determinísticos que usan una combinación entre expresiones matemáticas y mediciones realizadas para el cálculo de los niveles de intensidad de campo en función de la ubicación del punto de recepción (ITU-R P. 1812, 2013). En la medición de la cobertura de la señal de televisión digital terrestre -TDT, el parámetro que mayor incertidumbre genera tanto en los cálculos y las mediciones es el nivel de intensidad de campo recibido (lacob et al., 2018), debido al efecto de la difracción en los sitios donde la señal sufre desvanecimiento por obstrucción (Kateros et al, 2009; Östlin et al., 2008). Debido a esto, los modelos estadísticos y semi-determinísticos incluyen la parametrización que emula las condiciones de difracción a partir de la gran cantidad de mediciones realizadas en campo (Setiyanto et al., 2016).

En este artículo se realiza un análisis entre los modelos de propagación determinísticos recomendados por la Unión Internacional de Telecomunicaciones - ITU para el cálculo de las atenuaciones en el espacio libre ITUR P.525 y el cálculo de los niveles de intensidad de campo por la difracción Deygout 94 e ITU-R P.526; los modelos estadísticos de curvas de propagación ITU-R P.370 e ITU-R P.1546; y el modelo semi-determinístico para la predicción de propagación de servicios terrestres ITU-R P.1812. Estos modelos se utilizan para la planificación de redes de televisión digital terrestre en Colombia, con el propósito de seleccionar el que mejor se ajusta a las condiciones reales de propagación en el territorio bajo estudio.

\section{METODOLOGÍA}

Se realizan las simulaciones de los modelos de propagación determinísticos; utilizando geometrías de difracción cilíndricas y filo de cuchilla; modelos estadísticos, semi-deterministicos y se comparan los resultados obtenidos para un escenario de simulación que comprende zona urbana y rural. Se analiza la cobertura obtenida con cada modelo y se realizan mediciones en campo con el propósito de contrastar las mediciones con los resultados obtenidos. Finalmente se realiza un análisis estadístico de los resultados empleando una regresión lineal de los resultados obtenidos. La ubicación de la estación piloto permite tener línea de vista directa sobre la zona urbana de la ciudad de Medellín incluyendo el área metropolitana. Sin embargo, la mayor cobertura proporcionada por la estación transmisora se debe a los efectos de la difracción, dado que la mayor parte del territorio no posee línea de vista despejada con la estación. En la Tabla 1 se relacionan las características técnicas de la estación transmisora de televisión digital denominado padre Amaya, ubicado en zona rural del departamento de Antioquia-Colombia. Los efectos de la difracción se analizan a partir de los modelos de propagación y los resultados obtenidos en las mediciones en campo. La mayoría de los puntos medidos se localizan en zonas con obstrucción en la línea de vista entre el transmisor y los receptores.

Tabla 1: Características técnicas de la estación piloto de TDT.

\begin{tabular}{|l|l|l|}
\hline \multirow{2}{*}{ Coordenadas } & Latitud & $6^{\circ} 16^{\prime} 47,8^{\prime \prime} \mathrm{N}$ \\
\cline { 2 - 3 } & Longitud & $75^{\circ} 41^{\prime} 10,3^{\prime \prime} \mathrm{W}$ \\
\hline \multicolumn{2}{|l|}{ Altura } & $3098 \mathrm{msnm}$ \\
\hline Potencia de transmisión & $6000 \mathrm{~W}$ \\
\hline \multirow{4}{*}{ Arreglo de antenas } & Configuración & $(8: 8: 8: 8)$ \\
\cline { 2 - 3 } & Azimut & $\left(10^{\circ}: 100^{\circ}: 190^{\circ}: 280^{\circ}\right)$ \\
\cline { 2 - 3 } & Inclinación & $\left(1^{\circ}: 5^{\circ}: 1^{\circ}: 1^{\circ}\right)$ \\
\cline { 2 - 3 } & Relleno de nulos & $(10 \%: 20 \%: 10 \%: 10 \%)$ \\
\cline { 2 - 3 } & Ganancia del arreglo & $13,2 \mathrm{~dB}$ \\
\cline { 2 - 3 } & Centro de radiación & $136 \mathrm{~m}$ \\
\hline Pérdidas estimadas del sistema de transmisión & $2,88 \mathrm{~dB}$ \\
\hline
\end{tabular}




\section{Modelo determinístico ITU-R P.525 atenuación en el espacio libre}

En radiodifusión, el espacio libre es el medio de transmisión que se afecta debido a los fenómenos atmosféricos causantes de la absorción de la energía radioeléctrica (Finkenthal, et al, 1996). La ITU en su recomendación P.525 (ITU-R P.525-3, 2016) establece las expresiones para el cálculo de la atenuación por espacio libre en enlaces: punto a zona, punto a punto y radar. En la ecuación (1) se muestra la expresión de las pérdidas por espacio libre, incorporada en el modelo de propagación ITU-R P.525.

$$
L_{p f}=34,2+20 \cdot \log (f)+20 \cdot \log (d)
$$

El parámetro $L_{p f}$ corresponde a las pérdidas por transmisión en el espacio libre en decibelios, $f$ hace referencia a la frecuencia de transmisión en " $M H z$ ' y $d$ es la distancia entre el centro transmisor y el punto de recepción en " $k m$ ".

\section{Modelo determinístico ITU-R P.526 propagación por difracción}

La propagación de la señal radioeléctrica en presencia de obstáculos en su trayectoria presenta el fenómeno de difracción, cambiando la dirección en su trayectoria. En la recomendación ITU-R P.526 se proponen métodos que permiten el cálculo de los niveles de intensidad de campo debido a la propagación por difracción, donde los obstáculos se modelan con formas geométricas del tipo filo de cuchilla o redondeadas. El modelo también incluye el cálculo de las pérdidas debido las características eléctricas de admitancia de la superficie K (ITU-R P.526-13, 2013). En la Figura 1, se muestran las curvas del factor normalizado de admitancia de superficie $K$.

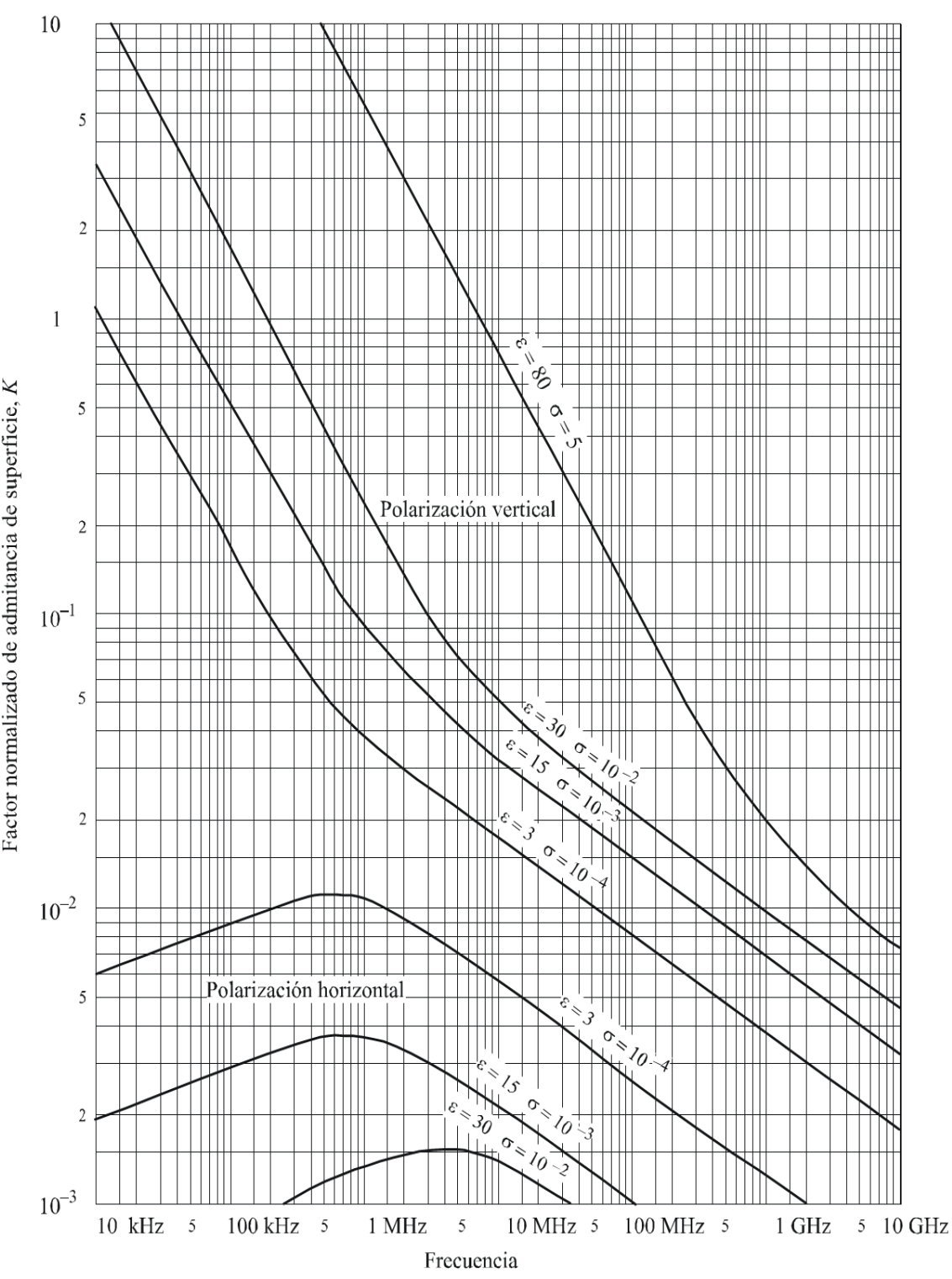

Fig. 1: Características eléctricas de la tierra. (Tomado de ITU-R P.526-13, 2013) 
El modelo ITU-R P.526 define el cálculo de los niveles de intensidad de campo de las señales, en un punto sin línea de vista directa, considerando el ángulo de difracción de las señales que se propagan hacia los picos de obstrucción, proponiendo un análisis puntual de la difracción por cada punto de obstrucción, de tal manera que los obstáculos se consideran independientemente, aumentando así el costo computacional. En la Figura 2, se observa a manera de ejemplo un escenario de transmisión por radiodifusión, donde no hay línea de vista entre el transmisor y el receptor, donde cada obstáculo se comporta como un repetidor.

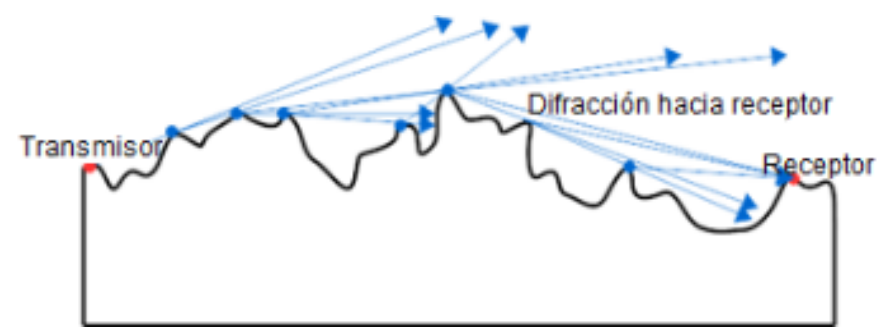

Fig. 2: Difracción para un trayecto transmisor-receptor sin línea de vista

\section{Modelo determinístico Deygout 94 difracción por agrupación de obstáculos}

El modelo Deygout 94 reduce el número de cálculos por obstáculo (Deygout, 1966), debido a que suma las pérdidas generadas por la agrupación de obstáculos que interceptan la primera zona de Fresnel. En la Figura 3 se muestra el efecto de la difracción por la incidencia de la señal trasmitida en un área muy pequeña en el pico más alto del obstáculo tipo filo de cuchilla.

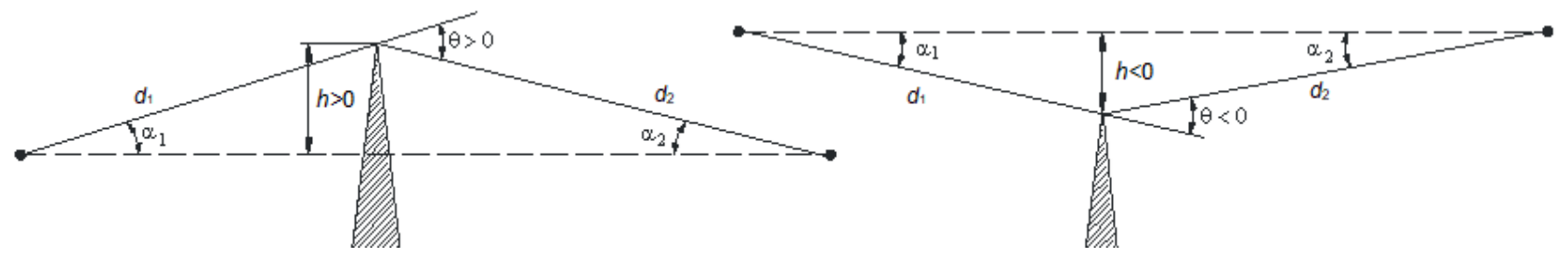

Fig. 3: Difracción por obstáculos tipo filo de cuchilla. (Tomada de J. Deygout, 1966)

\section{Modelo estadístico ITU-R P.370 curvas de propagación z}

La recomendación ITU-R P.370 establece una serie de curvas de nivel de intensidad de campo electromagnético en función de la distancia entre el transmisor y receptor, calculadas a partir de un número considerable de mediciones en campo en diferentes entornos. Las curvas se obtuvieron de mediciones realizadas en el continente europeo, en regiones influenciadas por mares cálidos y fríos. Como es usual en la planificación de redes, las curvas de los niveles de intensidad de campo se hallaron con antenas receptoras caracterizadas e instaladas a 10 metros de altura sobre el nivel del suelo, en dirección del centro transmisor. Esta premisa se incluyó con base en la recomendación ITU-R SM.1875 (ITU-R SM.1875-2, 2014), propuesta para mediciones de cobertura y verificación de criterios de planificación y simulaciones de propagación de señales. Otro aspecto importante considerado en el modelo ITU-R P.370 se refiere a la rugosidad del terreno $\Delta h$, con la cual se tiene en cuenta el factor que representa las ondulaciones típicas. En la Figura 4 se aprecia de manera gráfica el concepto de rugosidad que introduce el modelo para una distancia dada entre un punto transmisor y el borde esperado de cobertura (ITU-R P.370-7, 1995).

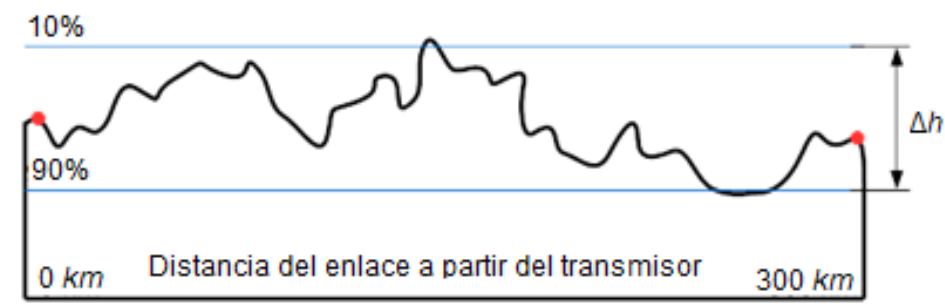

Fig. 4. Factor de rugosidad del terreno para los modelos estadísticos

Las curvas que se relacionan en la Figura 5 corresponden a los niveles de intensidad de campo experimentales para alturas del centro transmisor $h_{1}$, con respecto al punto de recepción, entre $37,5 \mathrm{~m}$ y 1200 $\mathrm{m}$ (ITU-R P.370-7, 1995). Las curvas se hallaron para valores de rugosidad típicos de $50 \mathrm{~m}$. En el evento en el que se requieran otros valores de rugosidad se debe aplicar el factor de corrección que se observa en la Figura 6. 


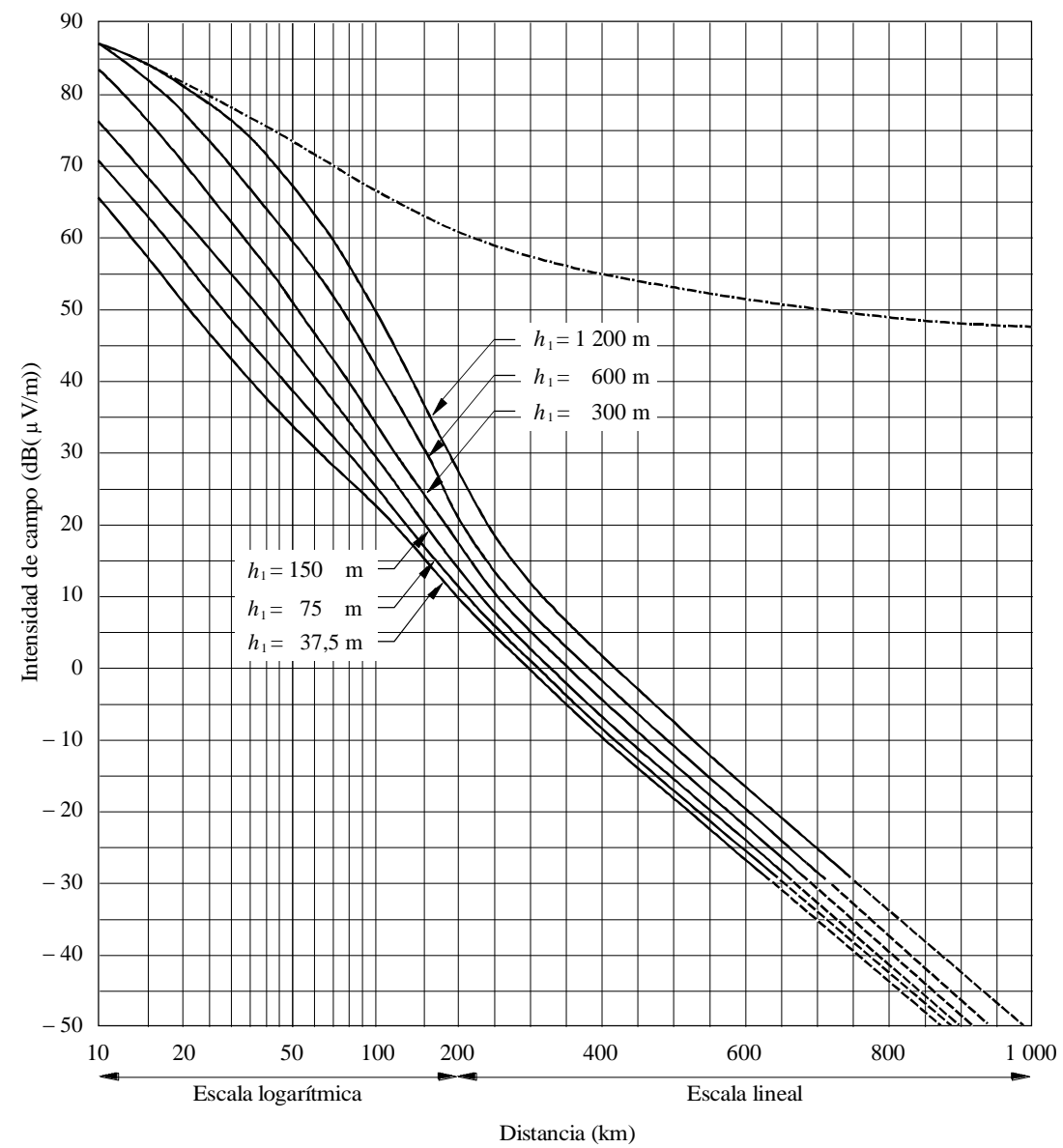

Fig. 5: Curvas de intensidad de campo para para trayecto terrestre en la banda de frecuencias $450 \mathrm{MHz}$ a $1000 \mathrm{MHz}$ (Tomado de ITU-R P.370-7, 1995)

\section{Modelo estadístico ITU-R P.1546 métodos de predicción}

De forma similar al modelo ITU-R P.370, el método de predicción de cobertura ITU-R P.1546 presenta una serie de resultados experimentales en forma de curvas para frecuencias específicas de transmisión en las bandas VHF y UHF. Se deben aplicar los factores de corrección correspondientes para el cálculo de los niveles de intensidad de campo en la frecuencia específica de transmisión. El modelo ITU-R P.1546 establece, además, parámetros dinámicos experimentales para el cálculo de pérdidas por el efecto de difracción de las señales. Con esta inclusión, los niveles de intensidad de campo se ven afectados por la rugosidad del terreno y por el grado de obstrucción de las zonas de Fresnel. En la Figura 7 se observan las curvas experimentales para el caso de trayectos terrestres a la frecuencia de trasmisión de $600 \mathrm{MHz}$ (ITU-R P.1546-5, 2013).

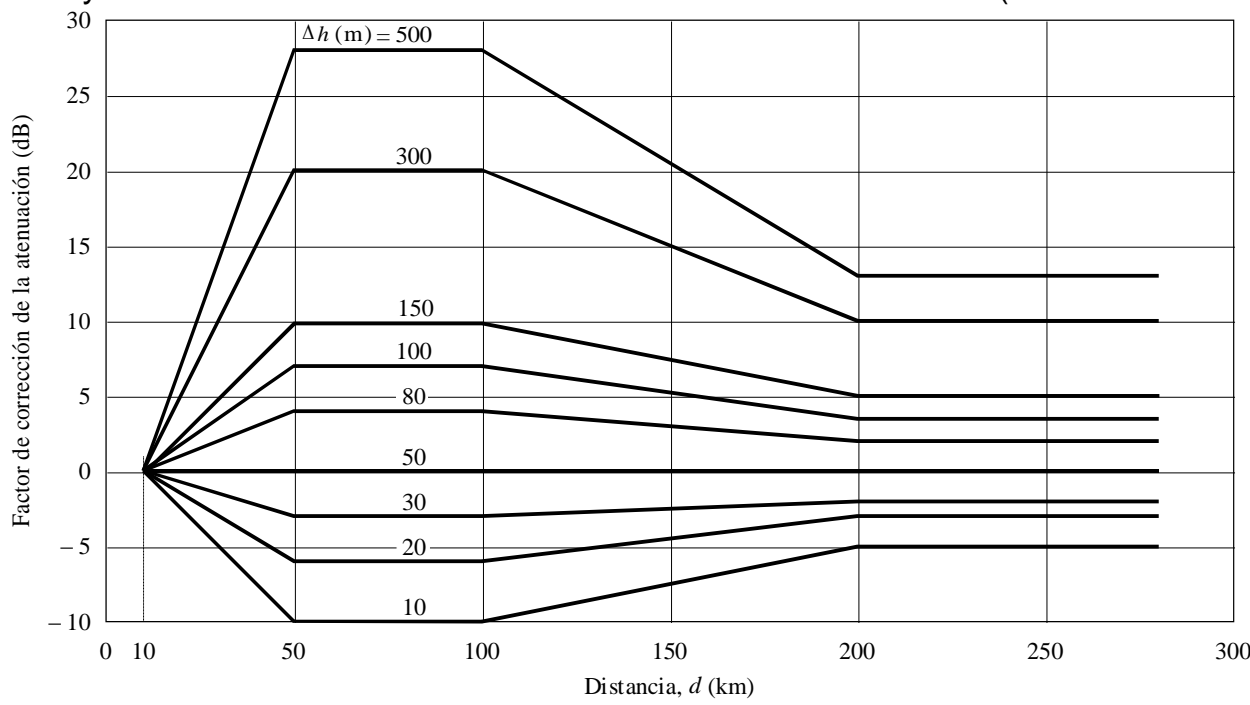

Fig. 6: Factor de corrección para la rugosidad del terreno en la banda de frecuencias de $450 \mathrm{MHz}$ a $1000 \mathrm{MHz}$ (Tomado de ITU-R P.370-7, 1995) 


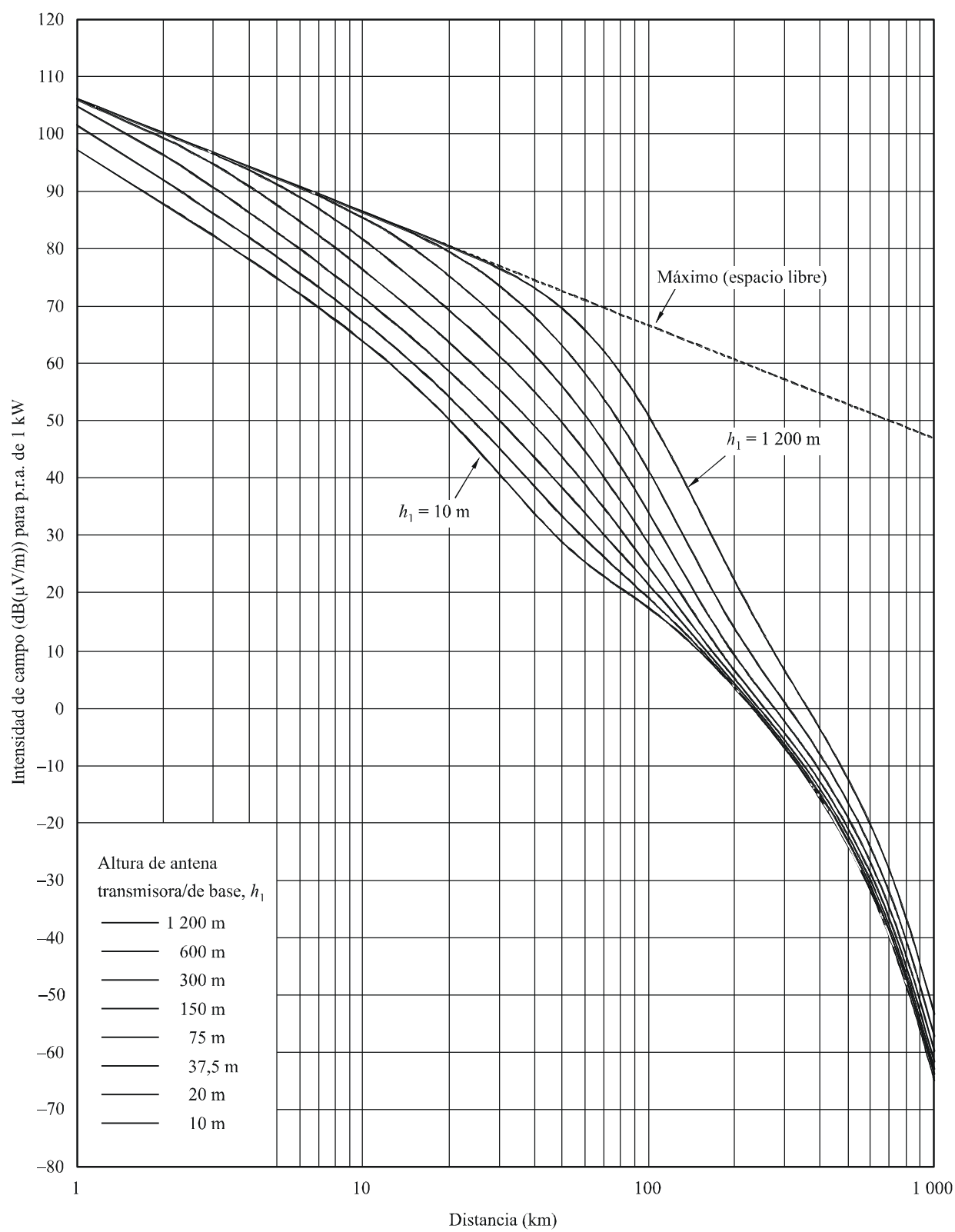

Fig. 7: Curvas de intensidad de campo para para trayecto terrestre, en la frecuencia de transmisión de 600 MHz (Tomado de ITU-R P.1546-5, 2013)

\section{Modelo semi-determinístico ITU-R P.1812}

El modelo de propagación radioeléctrica ITU-R P.1812 surge como complemento a la recomendación ITU-R P.1546 para la predicción de cobertura y análisis de los efectos de las señales no deseadas en frecuencias cocanal y canal adyacente. Este modelo introduce el cálculo de las pérdidas básicas de transmisión en el espacio libre y pérdidas debidas a la penetración en edificios para la estimación de niveles de intensidad de campo indoor (ITU-R P. 1812, 2013). El modelo ITU-R P.1812 propone un método de cálculo determinístico para la difracción, teniendo en cuenta los obstáculos y la curvatura de la tierra (modelo de tierra esférica). EI resultado final se obtiene mediante la combinación de las pérdidas calculadas en los dos escenarios. El cálculo del valor estimado de pérdidas para todos los trayectos, sean marítimos, costeros o terrestres, se realiza empleando una aproximación de las pérdidas por difracción para un único obstáculo tipo filo de cuchilla, utilizando la expresión (2) (ITU-R P. 1812, 2013).

$$
J(v)=6,9+20 \cdot \log \left(\sqrt{(v-0,1)^{2}+1}+v-0,1\right)
$$

Para el cálculo de la difracción total, el modelo establece expresiones matemáticas donde se consideran factores como la curvatura efectiva de la tierra, el trayecto de difracción transhorizonte y las pérdidas estimadas por obstáculos tipo filo de cuchilla. En la Figura 8 se muestran los resultados de las pérdidas estimadas en función del parámetro de obstrucción $v$. 


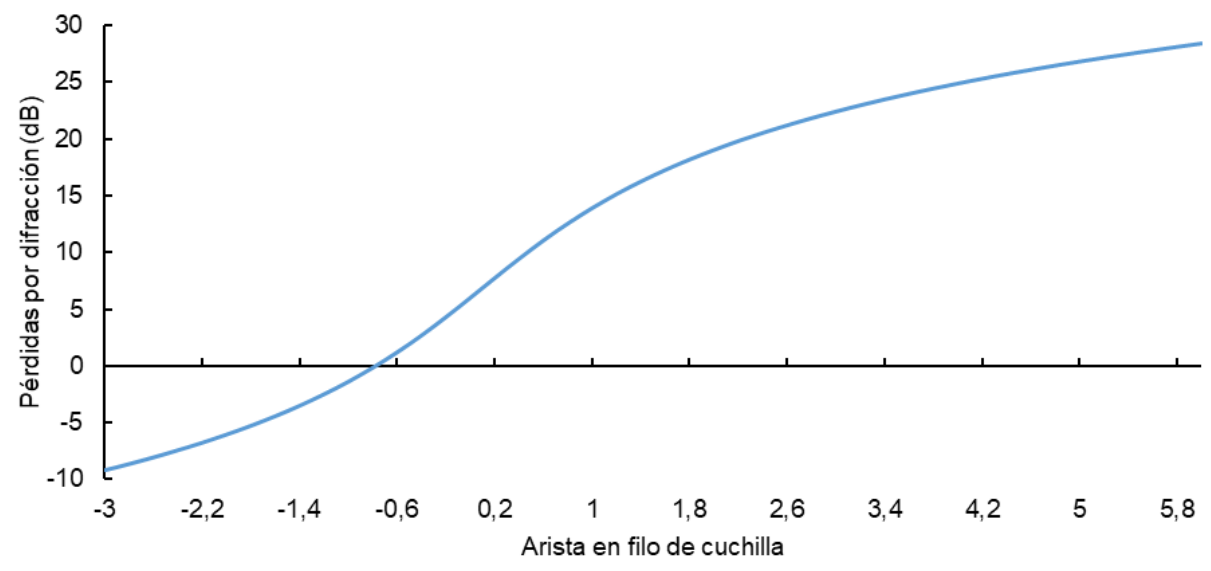

Fig. 8: Pérdidas por difracción en obstáculos tipo filo de cuchilla

\section{RESULTADOS}

Se presentan resultados de las simulaciones realizadas a los modelos considerados en este estudio: Modelo determinístico ITU-R P.525 atenuación en el espacio libre e ITU-R P.526 propagación por difracción, Modelo determinístico Deygout 94 difracción por agrupación de obstáculos, Simulaciones de propagación con los modelos determinísticos, Modelo estadístico ITU-R P.370 curvas de propagación z, Modelo estadístico ITUR P.1546 métodos de predicción, Simulación de propagación con los modelos estadísticos, Modelo semideterminístico ITU-R P.1812, y Simulación de propagación con el modelo semi-determinísticos ITU-R P.1812

\section{Simulaciones de propagación con los modelos determinísticos}

En las simulaciones se utilizan los modelos de propagación ITU-R 525 e ITU-R P.526, con geometrías de difracción cilíndricas y filo de cuchilla respectivamente. En las Figura 9 y la Figura 10 se muestran los resultados obtenidos en las simulaciones de propagación de señales radiodifundidas del servicio de televisión digital terrestre en la región de Antioquia-Colombia, donde el transmisor se configuró con los parámetros relacionados en la Tabla 1.

Los resultados obtenidos con el modelo ITU-R 525 muestran su aplicabilidad en las zonas con línea de vista despejada entre el transmisor y receptor. Los niveles de intensidad de la señal recibida resultan similares tanto en zona urbana como la zona rural. En las regiones donde la zona de Fresnel se obstruye total o parcialmente, es aplicable el modelo ITU-R P.526, originando la propagación de la señal por efecto de la difracción. También se observa que considerar obstáculos con formas geométricas cilíndricas conlleva asumir mayores pérdidas de propagación, teniendo en cuenta que el área de superficie en la que inciden las señales es mayor en comparación con los obstáculos tipo filo de cuchilla.

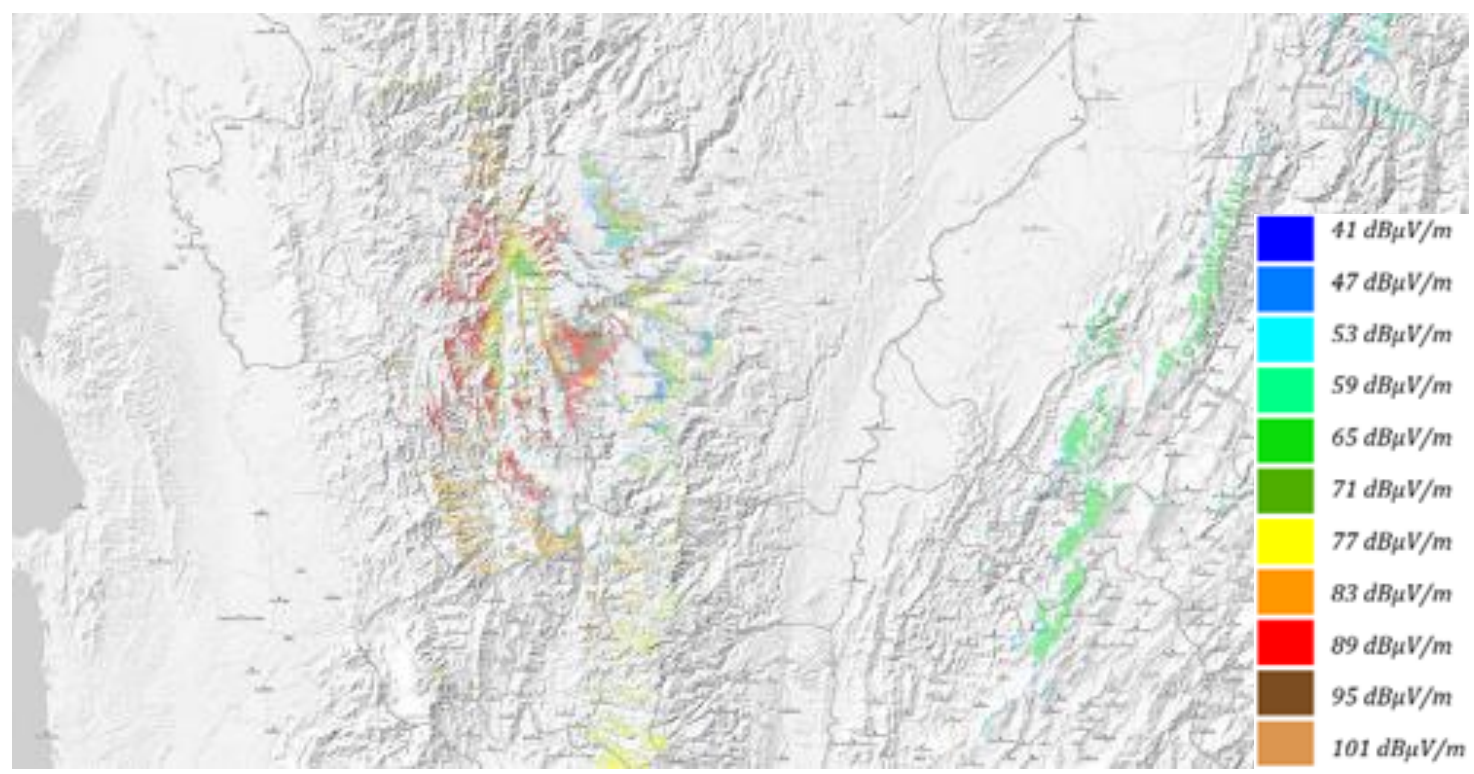

Fig. 9: Propagación de señales con el modelo ITU-R 525/ITU-R P.526, geometría de difracción cilíndrica 


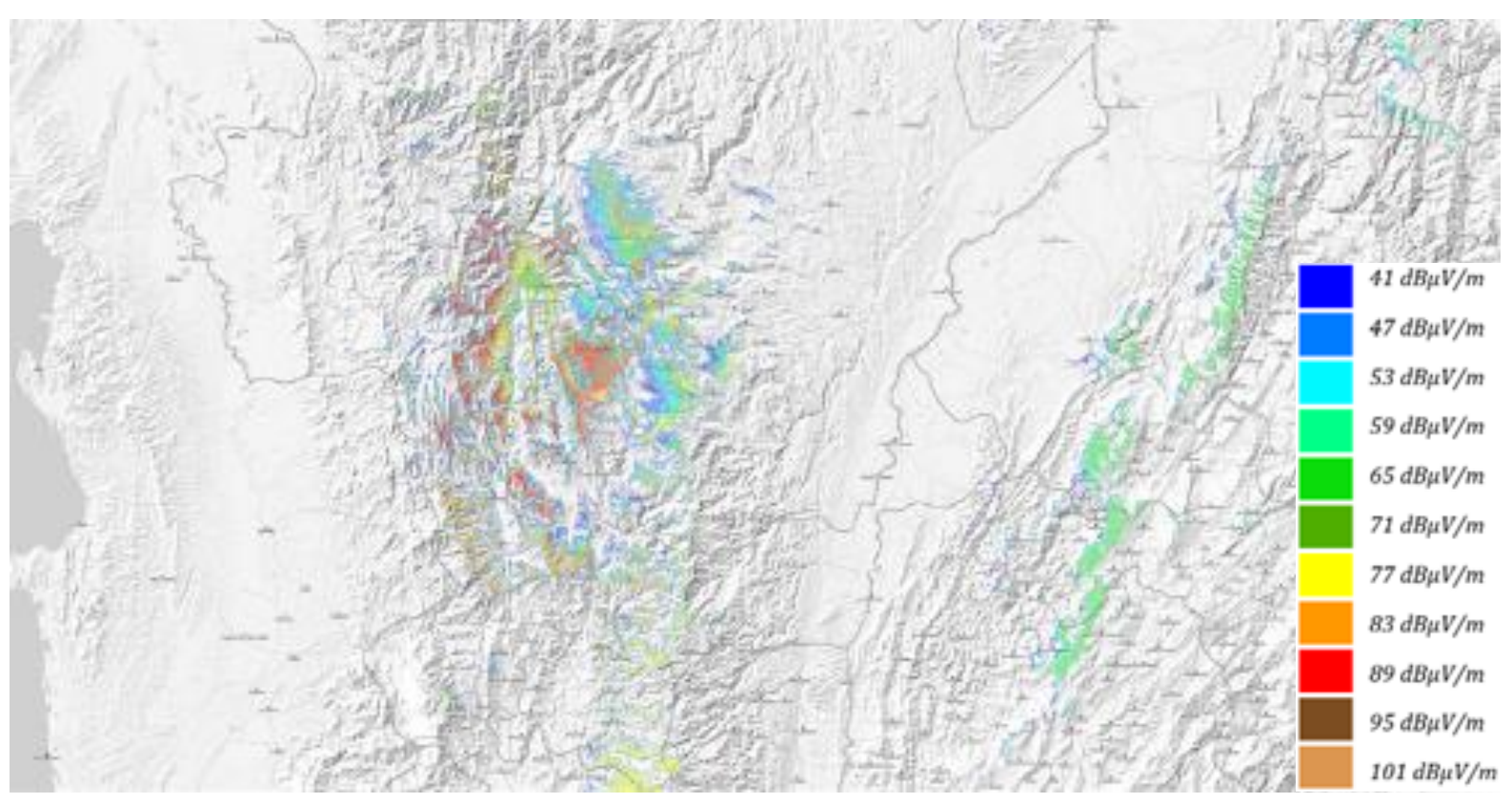

Fig. 10: Propagación de señales con el modelo ITU-R 525/ITU-R P.526, geometría de difracción filos de cuchilla

En la Figura 11 se observan los resultados obtenidos de las simulaciones de propagación con los modelos ITU-R 525 para el cálculo de intensidad de campo en puntos con línea de vista despejada y Deygout 94 para el cálculo de los niveles de intensidad de campo en áreas obstruidas. Debido a que el modelo de difracción Deygout 94 propone la agrupación de obstáculos entre transmisor y receptor con geometría tipo filo de cuchilla, los niveles de atenuación son menores en comparación con los modelos anteriores.

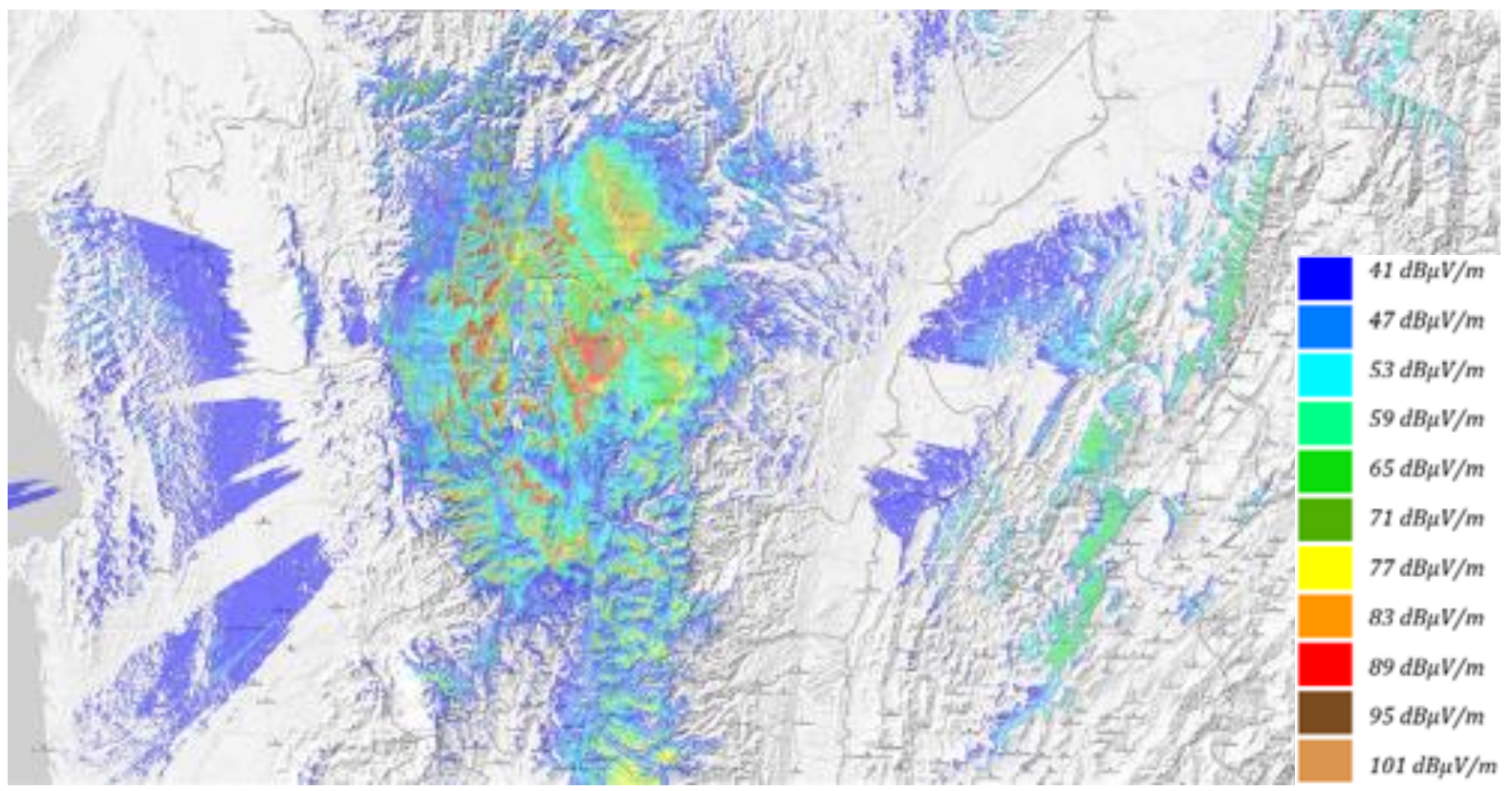

Fig. 11: Propagación de señales con el modelo ITU-R 525, geometría de difracción Deygout 94

\section{Simulación de propagación con los modelos estadísticos}

En la Figura 12 se observa el resultado de la simulación de propagación para la estación piloto haciendo uso del modelo ITU-R P.370 y la cartografía digital para el cálculo automático de la rugosidad del terreno. No obstante, con la mancha de cobertura se aprecia que la orografía del terreno causa un efecto mínimo sobre los resultados, teniendo en cuenta que la forma de la mancha se asemeja al diagrama de radiación de la antena transmisora, a pesar que la mayoría de los puntos de recepción no cuentan con línea de vista despejada. 


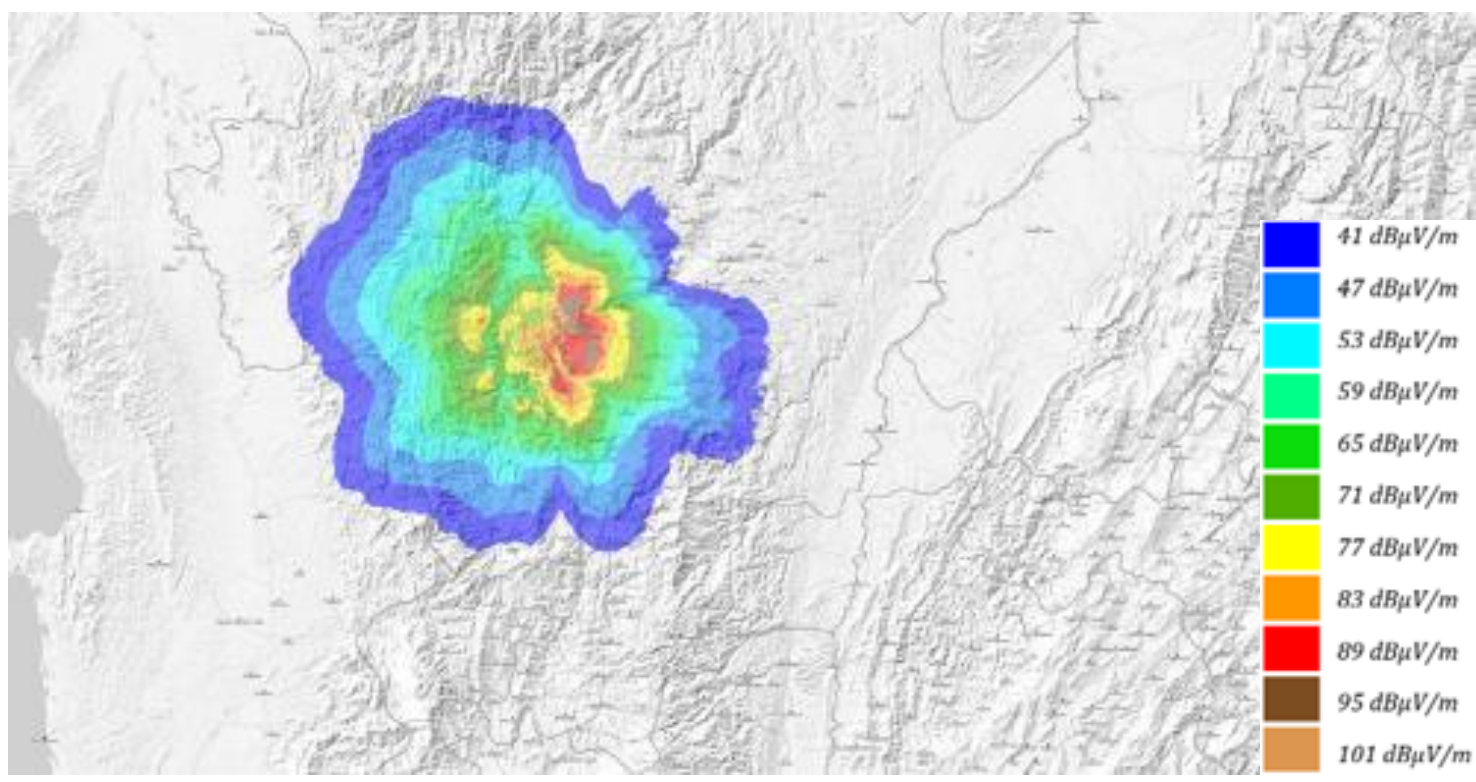

Fig. 12: Propagación de señales con el modelo ITU-R P.370

La Figura 13 corresponde a los resultados de propagación de la misma estación con el modelo ITU-R P.1546. El efecto de la aplicación de las curvas de atenuación de cada uno de los modelos es apreciable obteniendo, para el modelo ITU-R P.370 atenuaciones en función de la distancia de propagación y, en el segundo caso para el modelo ITU-R P.1546 atenuaciones en función de las cotas altimétricas del terreno. Para el modelo ITU-R P.1546 se observan niveles de intensidad de campo elevados en zonas muy alejadas al transmisor, a distancias entre $300 \mathrm{~km}$ y $400 \mathrm{~km}$; esto se debe a que las elevaciones en estas regiones son en gran medida menores a la del punto transmisor y con la aplicación del modelo ITU-R P.1546 se asumen pérdidas muy pequeñas o incluso nulas por el efecto de la difracción.

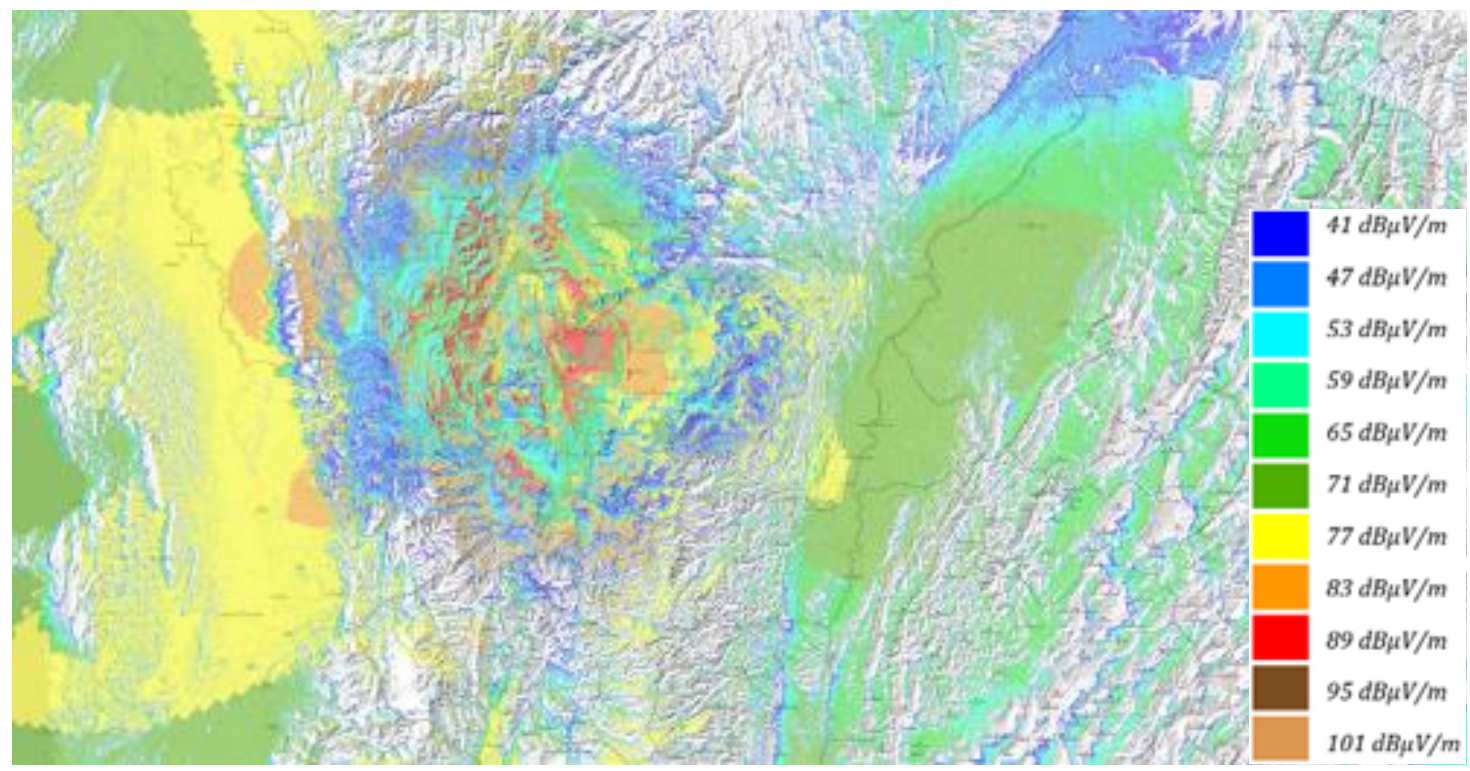

Fig. 13: Propagación de señales con el modelo ITU-R P.1546

\section{Simulación de propagación con el modelo semi-determinísticos ITU-R P.1812}

La predicción de propagación de señales con el modelo ITU-R P. 1812 se observa en la Figura 14. A pesar de que este modelo parte de curvas experimentales, la inclusión de expresiones para el cálculo de atenuaciones por difracción plantea un nuevo escenario de propagación que, en comparación con el modelo netamente estadístico ITU-R P. 1546, se puede considerar más realista. El resultado de predicción de cobertura con el modelo ITU-R P. 1812 se asemeja a los resultados obtenidos con los modelos determinísticos, especialmente con los escenarios donde se consideraron geometrías de difracción tipo filo de cuchilla. Es así que, necesariamente, la elección de uno de estos modelos depende sustancialmente de los resultados comparativos con mediciones en campo. 


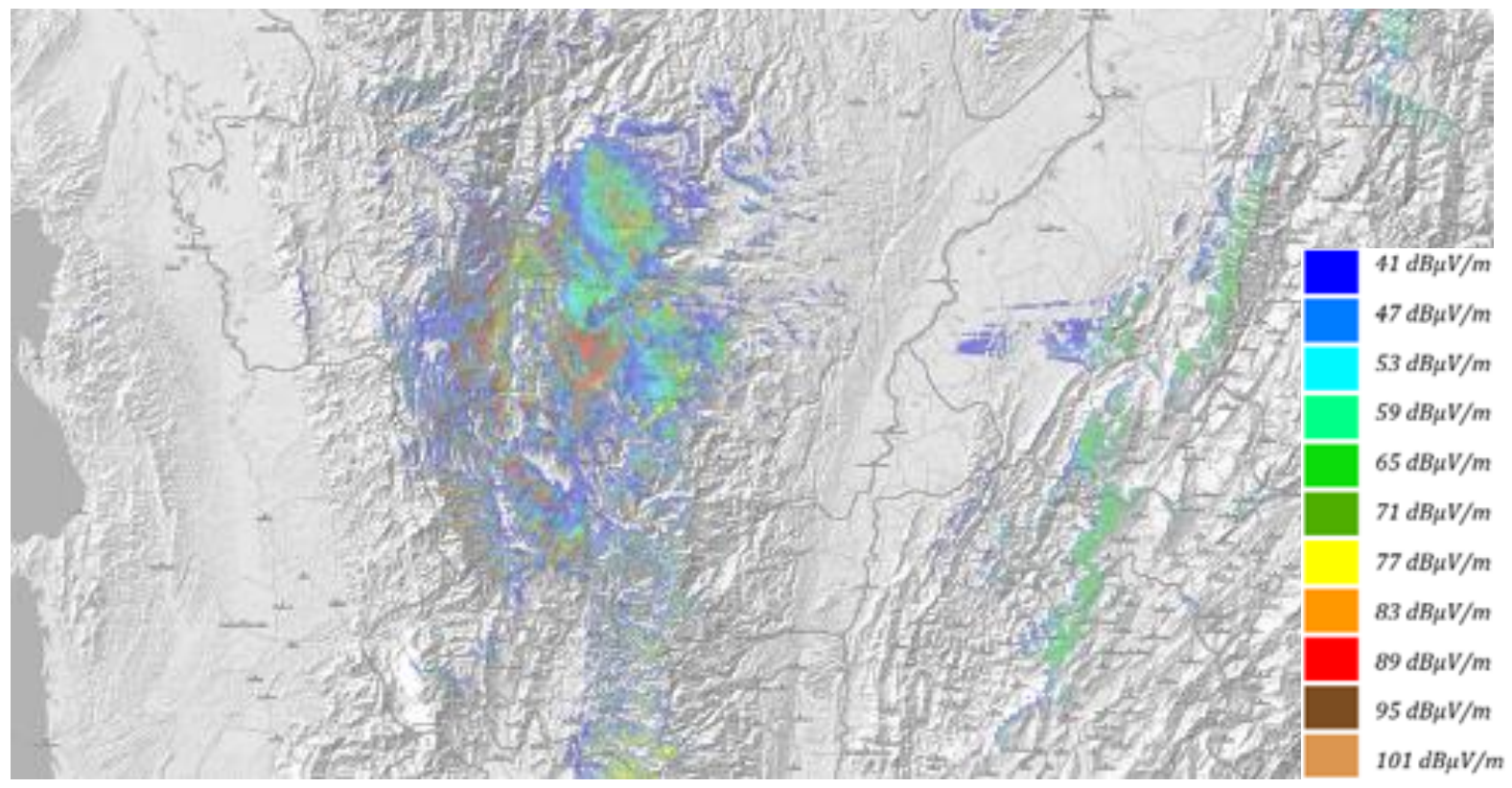

Fig. 14: Propagación de señales con el modelo ITU-R P.1812

\section{ANÁLISIS DE RESULTADOS}

El análisis comparativo entre las mediciones realizadas en campo y los niveles de intensidad de campo simulados revela que existen modelos cuya propagación de señales es pesimista u optimista con respecto a las mediciones en campo. Para determinar la fiabilidad de los modelos de propagación es preciso estimar los valores medios, varianza y desviaciones estándar de las diferencias absolutas entre las mediciones en campo y cada uno de los resultados. Las diferencias hacen referencia al grado de error de las predicciones con respecto a un escenario real, considerando que el error es directamente proporcional a la magnitud de las estimaciones. En la Tabla 2 se relacionan las estimaciones estadísticas para cada uno de los modelos, considerando los valores absolutos de las diferencias entre los resultados simulados y las mediciones en campo. Se observa que los modelos de propagación que mayor error arrojan corresponden a los modelos ITU-R 525/ITU-R P.526 (determinísticos), ITU-R P.370 e ITU-R P.1546 (estadísticos), en razón a que los valores de la media y la varianza del error resultan relativamente altos.

Tabla 2. Estimaciones de las diferencias absolutas entre resultados y medidas en campo

\begin{tabular}{|l|c|c|c|c|c|c|}
\hline Estimación & ITU-R P.526 CilindroS & ITU-R P.526 FiloS & ITU-R 525 DeygouT & ITU-R P.370 & ITU-R P.1546 & ITU-R P.1812 \\
\hline Valor medio & 28,92 & 14,38 & 7,14 & 15,41 & 13,63 & 8,92 \\
\hline Varianza & 401,18 & 163,77 & 42,35 & 82,33 & 132,35 & 56,95 \\
\hline $\begin{array}{l}\text { Desviación } \\
\text { estándar }\end{array}$ & 20,03 & 12,8 & 6,51 & 9,07 & 11,5 & 7,55 \\
\hline
\end{tabular}

Los modelos más aproximados a las mediciones en campo corresponden a las recomendaciones ITU-R 525 con geometrías de difracción Deygout 94 e ITU-R P.1812. El modelo determinístico ITU-R 525/Deygout 94 genera resultados más cercanos a los medidos en campo, dado que la magnitud de la variabilidad del error es menor con respecto a los demás modelos.

Para identificar el modelo que más se aproxima a las mediciones en campo, resulta conveniente utilizar otro método de análisis complementario, a partir de un análisis de los resultados obtenidos aplicando una regresión lineal y en conjunto con la variabilidad, permite la observación de tendencias. La regresión lineal simple permite identificar las rectas de tendencia de las agrupaciones de datos donde los puntos de medición y comparación corresponden a la variable aleatoria independiente $\mathrm{Xi}$, y los niveles de intensidad de campo medidos y simulados corresponden la variable aleatoria dependiente $\mathrm{Yi}$, con la forma $\mathrm{Yi}=\beta \mathrm{O}+\beta 1 \mathrm{Xi}(\mathrm{O}$. I. Sheluhin, et al, 2007). Cada recta Yi depende de los parámetros $\beta$ o y $\beta 1$, que corresponden a su vez a la posición y a la pendiente de cada recta calculados con la expresión (3).

$$
\hat{\beta}_{0}=\bar{y}-\hat{\beta}_{1} \bar{x} \quad \text { y } \quad \hat{\beta}_{1}=\frac{\sum(x-\bar{x})(y-\bar{y})}{\sum(x-\bar{x})^{2}}
$$


La precisión en los modelos de propagación es equivalente a la aproximación, en posición y pendiente, entre las rectas resultantes de las simulaciones y la recta correspondiente a las mediciones en campo. En la Figura 15 se presentan los resultados gráficos de la regresión lineal comparativa. Con las rectas calculadas se observa que los modelos de propagación ITU-R 525/ITU-R P.526 Cilindros, ITU-R P.370 e ITU-R P.1546, no se asemejan con los resultados en campo, teniendo en cuenta las direcciones de cada recta. Con esta misma condición se afirma que los modelos cuya tendencia se asemejan a los datos reales, corresponden a ITU-R 525/ITU-R P.526 filos de cuchilla, ITU-R 525 Deygout 94 e ITU-R P.1812. No obstante, el modelo que más se aproxima a la realidad, dada la tendencia y la proximidad de su recta con respecto a las mediciones en campo, corresponde al método ITU-R 525 Deygout 94, donde la diferencia en posición representa el error. Con la caracterización adecuada de los elementos de medición el error estimado puede ser compensado con inclusión de un factor de corrección aplicado a las simulaciones.

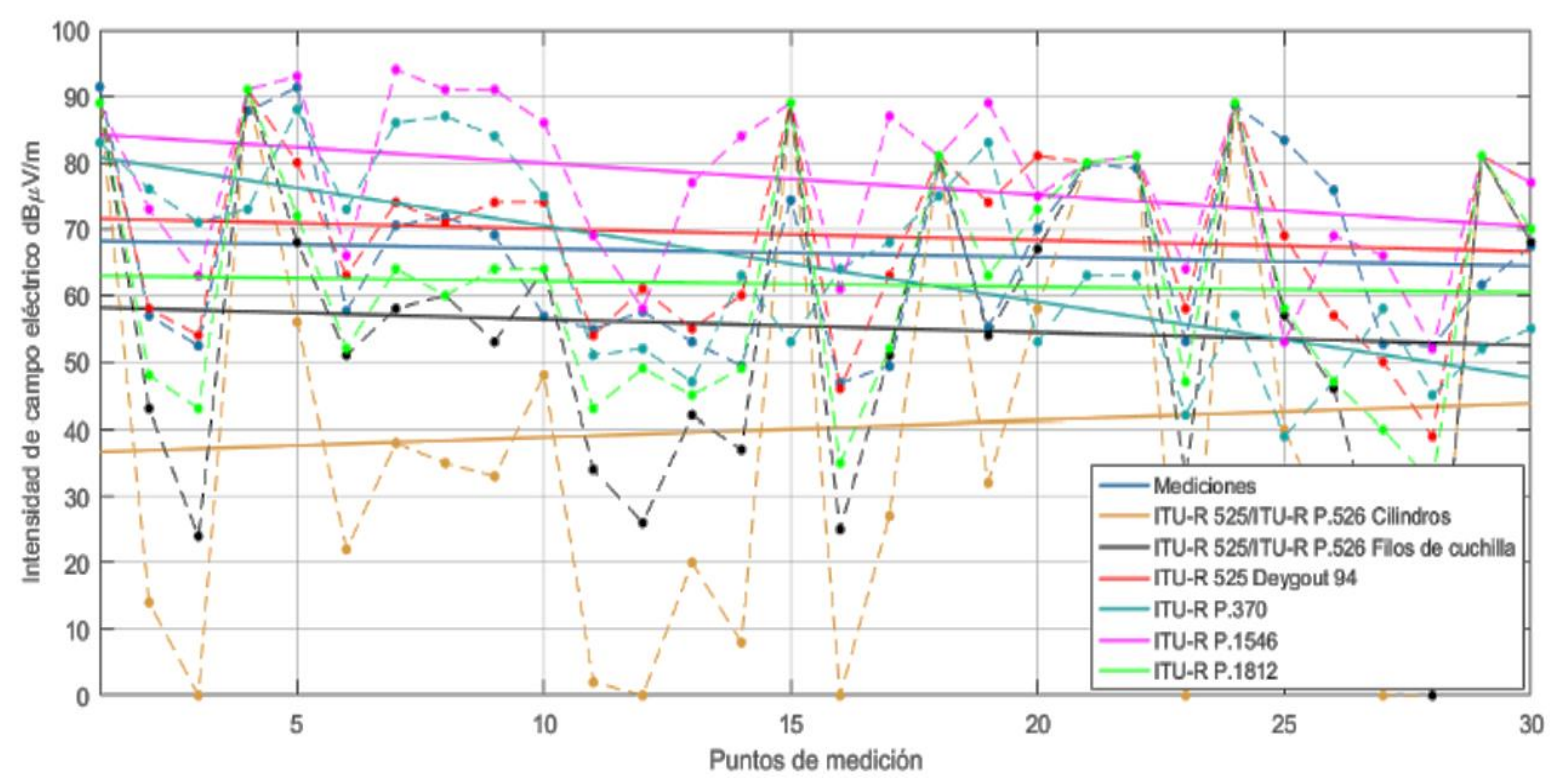

Fig. 15: Regresión lineal de las mediciones en campo y los resultados de los modelos de propagación simulados

\section{DISCUSIÓN FINAL}

La eficacia en la identificación del modelo idóneo es producto, básicamente, de la comparación de las mediciones de cobertura y los niveles de intensidad de campo simulados de un sistema de transmisión de televisión digital terrestre para entornos urbanos y rurales de Colombia. En ese sentido, el modelo establecido como el más apropiado para la simulación de redes de televisión puede extenderse a otros servicios que se transmitan en la banda UHF, teniendo en cuenta que la comparación sólo incluye el análisis de los niveles de intensidad de campo en puntos con línea de vista despejada y obstruida, aspectos que comparten todos los servicios del tipo punto a zona.

Con los resultados de cada modelo de propagación y las mediciones en campo se corroboró que el efecto diferenciador de las coberturas simuladas está dado por la difracción de las señales. En entornos con línea de vista despejada los resultados de los niveles de intensidad de campo de cada modelo de propagación son comparativamente semejantes entre sí. Es decir que, en condiciones ideales de despeje de línea de vista entre la estación transmisora y los receptores, se puede hacer uso de cualquier modelo de propagación aplicando ciertos factores de ajuste. Por otro lado, cuando la cobertura está dada por la difracción, los niveles de intensidad de campo en las zonas con línea de vista obstruida varían drásticamente.

El análisis estadístico realizado proporciona información del error estimado entre los valores medidos y los simulados para los modelos que más se ajustan al escenario real, como lo son el modelo ITU-R 525/Deygout 94 e ITU-R P.1812. Con la magnitud de este error se pueden compensar los resultados simulados agregando un factor de corrección, en este caso de pérdidas en los sistemas de transmisión. No obstante, en el análisis estadístico también se incluyeron ciertos factores de error por cuenta de la estimación de pérdidas y ganancia del set de mediciones y la caracterización del sistema radiación. En ese caso se hace necesaria la caracterización previa de todos los elementos de medición y de la forma geométrica del patrón de radiación de los sistemas radiantes a fin de establecer un factor ajustado de compensación.

Usando la regresión lineal se identificó el modelo de propagación que más se aproxima al escenario real de radiodifusión de señales de televisión en la banda UHF en entornos urbanos y rurales de Colombia, que 
corresponde a una combinación de los modelos determinísticos ITU-R 525 para entornos con línea de vista despejada y el modelo Deygout 94 para entornos con línea de vista obstruida. Si bien la regresión lineal se aplica de manera independiente para las mediciones en campo y para cada modelo, el análisis de las pendientes de las rectas resultantes y la proximidad entre éstas proporciona información confiable en cuanto a la tendencia y similitud de los datos.

\section{CONCLUSIONES}

De acuerdo al trabajo presentado y a los resultados obtenidos, se pueden plantear las siguientes conclusiones principales: 1) el análisis estadístico obtenido en la comparación entre las simulaciones obtenidas y las mediciones de campo para zonas rurales y urbanas en Colombia, permiten identificar que los modelos de propagación determinísticos ITU-R 525/ITU-R P.526 filos de cuchilla, ITU-R Deygout 94 y semi-determinístico ITU-R P.1812 tienden a asemejarse a los datos reales, mientras que los modelos de propagación estadísticos ITU-R P.370 e ITU-R P.1546 arrojan mayores errores; 2) la precisión del modelo de propagación aplicado a los entornos urbanos y rurales está determinada por la difracción de las señales radiodifundidas del servicio de televisión digital terrestres. En regiones donde hay liberación de línea de vista entre la estación transmisora y los receptores, existe similitud en los niveles de intensidad de campo obtenidos. Esto permite utilizar un factor de ajuste en los modelos a partir de las mediciones de campo realizadas; 3 ) los modelos de propagación recomendados para el análisis de cobertura de la señal de televisión digital terrestre en zonas con obstrucción de línea de vista entre la estación transmisora y los receptores son las recomendaciones ITU-R 525 con geometrías de difracción Deygout 94 e ITU-R P.182, dado al menor error comparativo con las mediciones realizadas en campo.

\section{AGRADECIMIENTOS}

Esta investigación es financiada por el Centro de Investigación y Desarrollo Científico de la Universidad Distrital Francisco José de Caldas - CIDC (Proyecto: Metodología para el diseño y planificación de redes de televisión digital terrestre en entornos urbanos y rurales de Colombia, Código: 4-45-525-2016).

\section{REFERENCIAS}

ANE, Agencia Nacional del Espectro., Resolución ANE No. 668 - Por la cual se modifica la Resolución 37 del 20 de enero de 2012, atribución de bandas de frecuencia para televisión (2012)

Astawa, I.G.P. y Santoso T.B., Analysis Of performance DVB-T2 using MIMO system over MMSE channel estimation. 2016 IEEE Region 10 Symposium (TENSYMP), doi.org/10.1109/TENCONSpring.2016.7519422, 299-304 (2016)

Avellaneda, J.V., Rodríguez J.R. y López D.A., Servicios de televisión sobre la plataforma de internet (IPTV-IMS) usando protocolo de flujo en tiempo real (RTSP) y protocolo de transferencia de hipertexto (HTTP), doi.org/10.4067/S071807642014000100008, Información Tecnológica, 25(1), 67-76 (2014)

Cuéllar, J.C., Ortiz J.H. y Arciniegas J.L., Clasificación y Análisis de Métodos para medir Calidad de la Experiencia del Servicio de Televisión sobre Protocolo IP (IPTV), doi.org/10.4067/S0718-07642014000500017, Información Tecnológica, 25(5), 121-128 (2014)

Deygout, J., Multiple knife-edge diffraction of microwaves, doi.org/10.1109/TAP.1966.1138719, IEEE Transactions on Antennas and Propagation, 14(4), 480-489 (1966)

Eizmendi, I., Velez M.y otros 5 autores, DVB-T2: The Second Generation of Terrestrial Digital Video Broadcasting System, doi.org/10.1109/TBC.2014.231281, IEEE Transactions on Broadcasting, 60(2), 258-271 (2014)

Finkenthal, D. y otros 5 autores. Introduction to the Electromagnetic Spectrum, General Atomics (1996)

lacob, M.I., Demciuc Y.I. y Avraam I.A., Comparative evaluation of received signal parameters in SFN DVB-T2 service area, doi.org/10.1109/SYNCHROINFO.2018.8456937, Systems of Signal Synchronization, Generating and Processing in Telecommunications (SYNCHROINFO), 1-6 (2018)

ITU-R P.370-7: International Telecommunication Union (Switzerland), VHF and UHF propagation curves for the frequency range from $30 \mathrm{MHz}$ to $1000 \mathrm{MHz}$, ITU/CCIR: Recommendations and Reports of the CCIR (1995)

ITU-R P.1546-5: International Telecommunication Union (Switzerland), Method for point-to-area predictions for terrestrial services in the frequency range $30 \mathrm{MHz}$ to $3000 \mathrm{MHz}$, Electronic Publication, P-Series (2013)

ITU-R P.526-13: International Telecommunication Union (Switzerland), Propagation by diffraction, Vol. 11 (2013)

ITU-R SM.1875-2: International Telecommunication Union (Switzerland), DVB-T Coverage measurements and verification of planning criteria, Vol. 2 (2014)

ITU-R P. 1812: International Telecommunication Union (Switzerland), A path-specific propagation prediction method for point-to-area terrestrial services in the VHF and UHF bands, Vol. 1, 1-30 (2015) 
ITU-R P.525-3: International Telecommunication Union (Switzerland), Calculation of free-space attenuation, P Series Radiowave Propagation, Vol. 3 (2016)

Jokela, T., Tupala M. y Paavola J., Analysis of physical layer signaling transmission in DVB-T2 systems, doi.org/10.1109/TBC.2010.2051497, IEEE Transactions on Broadcasting, 56(3), 410-417 (2010)

Kateros, D.A. y otros 6 autores, DVB-T Network planning: a case study for Greece, doi.org/10.1109/MAP.2009.4939022, IEEE Antennas and Propagation Magazine, 51(1), 91-101 (2009)

Peña, J.E.A, Simulation of radiopropagation coverage in a fixed reception network of DVB-T2 digital terrestrial television: Metropolitan scenario of Bogotá D.C. (Colombia), doi.org/10.1109/CONIITI.2017.8273349, Congreso Internacional de Innovacion y Tendencias En Ingeniería (CONIITI), 1-6 (2017)

Östlin, E., Suzuki H. y Zepernick H.J., Evaluation of the propagation model recommendation ITU-R P.1546 for mobile services in rural Australia, doi.org/10.1109/TVT.2007.901902, IEEE Transactions on Vehicular Technology, 57(1), 38-51 (2008)

Setiyanto, B., Hidayat R., Mustika I.W. y Sunarno, Spatial-variation of DVB-T2 signal at the receiver-location, doi.org/10.1109/INAES.2016.7821928, 6th International Annual Engineering Seminar (InAES), 170-175 (2016)

Vargas-Arcila, A.M., Baldassarri S. y Arciniegas J.L., Análisis de Esquemas de Metadatos para la Marcación de Contenidos Multimedia en Televisión Digital, doi.org/10.4067/S0718-07642015000600016, Información Tecnológica, 26(6), 139-154 (2015)

Sheluhin, O.I., Smolskiy S.M. y Osin A.V., Self-similar processes in telecommunications, 177-207, 1ª Ed., John Wiley \& Sons, Southern Gate, England (2007) 
